\section{Shiga toxin-producing Escherichia coli in meat and vegetable products in Emilia Romagna Region, years 2012-2013}

\author{
Lia Bardasi, ${ }^{1}$ Roberta Taddei, ${ }^{1}$ \\ Lucia Nocera, ${ }^{2}$ Matteo Ricchi, ${ }^{3}$ \\ Giuseppe Merialdi ${ }^{1}$
}

1/stituto Zooprofilattico Sperimentale della Lombardia e dell'Emilia Romagna, Bologna; 'Regione Emilia Romagna, Bologna; ${ }^{3}$ Istituto Zooprofilattico Sperimentale della Lombardia e dell'Emilia Romagna, Piacenza, Italy

\section{Abstract}

In 2012-2013 Emilia-Romagna Region introduced a monitoring plan for Shiga toxin-producing Escherichia coli (STEC) in foodstuff. Six hundred eighty-nine meat samples and 273 fruit and vegetable products were analyzed according to ISOTS13136. Pre-enriched samples were tested by multiplex real time PCR targeting the virulence genes eae, stxl and stx2. Stx 2 positive samples were investigated for the presence of serogroup 0104 associated gene. 0103, 0111, 0145, 0157, 026 associated genes were tested on samples positive for $s t x$ in association with eae gene. Isolation of $E$. coli strains was attempted from samples positive for serogroup-associated genes. Thirtyfour meat products (4.9\%) resulted positive for $s t x 1$ and/or stx 2 genes and 46 (6.7\%) for $s t x 1$ and/or stx2 genes in association with eae gene. Forty-five (6.5\%) samples resulted positive at least at one serogroup. Serogroup 0103, 0104, $0111,0145,0157$ and 026 genes were detected respectively in 1.3, 0.3, 0.1, 3.9, 2.9 and $2.5 \%$ samples; $0.6 \%$ samples resulted positive for STEC isolation ( 2 E. coli 0103 and 2 E. coli 0157). It is worth noting that STEC virulence genes were detected at high frequency (19\%) in fresh pork meat sausages. Four (1.5\%) vegetable samples were positive for $s t x 1$ and/or stx 2 genes and $1(0.4 \%)$ for $s t x 1$ and/or stx 2 genes in association with eae gene; none resulted positive for the tested serogroups.

Only a low number of samples positive by molecular methods were confirmed by cultural isolation. It is therefore of the uttermost importance for appropriate risk management, to be fully aware of the meaning of the analytical result.

\section{Introduction}

Shiga toxin-producing Escherichia coli (STEC) are a group of highly pathogenic $E$. coli strains producing two phage-encoded cytotoxins, called Shiga toxins (Stx1 and Stx2), which are the common feature and main virulence factors of STEC and are directly correlated with human pathogenicity (Lindgren et al., 1993). In addition, some STEC strains are also able to attach to intestinal epithelial cells and form attaching and effacing lesions through an adhesin called intimin, which is encoded by the eae gene. The lower intestinal tract of ruminants is considered to be the main reservoir of STEC. STEC comprises serologically different strains; $E$. coli $0157: \mathrm{H} 7$ is the serotype that has been linked to most of the outbreaks of food-borne disease and has led to the largest number of hemolytic uremic syndrome (HUS) cases in humans. However, there is increasing evidence that also other serotypes can cause serious illness in humans (Caprioli et al., 1997, 2005). In most human infections, transmission occurs primarily by ingestion of contaminated food: most often inadequately cooked meat, especially minced beef, raw milk and raw milk products and ready to eat (RTE) products as fresh fruit and vegetables. Following E. coli 0104:H4 outbreak occurred in Germany in May 2011, Emilia Romagna Region instituted in 2012 a testing program for 0157 , 026, 0111, 0103, 0145 and 0104:H4 STEC, both at production and at retail level, for foodstuff considered at risk of contamination.

The aim of this study is to report on STEC detection in Emilia Romagna Region during the 2012-2013 monitoring plan, the extent of contamination in each food category analyzed is also considered.

\section{Materials and Methods}

A total of 689 meat and 273 vegetable samples were collected in Emilia Romagna Region from retail outlets, large retailers and processing plants. Meat samples comprised fresh meat pork sausages, minced meat and processed meat products (as skewer, breaded cutlet, roast meat, etc.) made of meat from different species here grouped in poultry meat and meat from species other than poultry. Vegetable samples comprised pre-cut fruits and vegetables, seeds and sprouted seeds. All meat samples were to be eaten after cooking while vegetable and fruit samples were all RTE. The sampling procedure was not uniform since the 689 meat samples were composed by 553 samples constituted of 1 sample unit and 136 samples constituted of 5 sample units. Similarly, the 273 vegetable and fruit samples were com-
Correspondence: Lia Bardasi, Istituto Zooprofilattico Sperimentale della Lombardia e dell'Emilia Romagna, via Pietro Fiorini 5, 40121 Bologna, Italy.

Tel: +39.051.4200037 - Fax: +39.051.4200038. E-mail: lia.bardasi@izsler.it

Key words: Shiga toxin, Escherichia coli, Food surveillance, Meat product, Ready-to-eat food.

Received for publication: 7 July 2014.

Revision received: 8 November 2014

Accepted for publication: 8 November 2014.

This work is licensed under a Creative Commons Attribution 3.0 License (by-nc 3.0).

(C) Copyright L. Bardasi et al., 2015

Licensee PAGEPress, Italy

Italian Journal of Food Safety 2015; 4:4511

doi:10.4081/ijfs.2015.4511

posed by 143 samples constituted of 1 sample unit and 130 samples constituted of 5 sample units. These samples were analyzed according to ISO TS 13136 (draft version).

Twenty-five $g$ of each sample were diluted ten-fold $(\mathrm{w} / \mathrm{v})$ in $225 \mathrm{~mL}$ of the recommended enrichment broth and incubated at $37 \pm 1^{\circ} \mathrm{C}$ for $21 \pm 3 \mathrm{~h}$. Bacterial DNA was extracted from 1 $\mathrm{mL}$ of enriched broth using Gen elute ${ }^{\mathrm{TM}}$ bacterial genomic DNA kit (Sigma-Aldrich, St. Louis, M0, USA) as described by the manufacturer. All primers and probes used in this study are reported in ISO 13136:2012 and published previously (ISO, 2012; Perelle et al., 2004; Nielsen and Andersen, 2003).

Multiplex real time PCR targeting the virulence genes eae, stx 1 and $s t x 2$ was conducted in a $25 \mu \mathrm{L}$ reaction volume using the following reaction mixture: $1 \mathrm{X}$ Taqman ${ }^{\circledR}$ Universal PCR Master mix (Applied Biosystems, Carlsbad, CA, USA), $450 \mathrm{nM}$ each of the forward and reverse primers, $100 \mathrm{nM}$ of each labeled probe and $4 \mu \mathrm{L}$ DNA template. A commercially available TaqMan ${ }^{\circledR}$ Exogenous Internal Positive Control (Applied Biosystems) was included in each PCR reaction. Real time-PCR thermal cycling was conducted using a StepOne Plus system (Applied Biosystems). The cycling parameters were: $95^{\circ} \mathrm{C}$ hold for $10 \mathrm{~min}$ for initial denaturation of the DNA and activation of the hot-start Taq polymerase, followed by 40 cycles of amplification of $95^{\circ} \mathrm{C}$ for $15 \mathrm{~s}$, and $60^{\circ} \mathrm{C}$ for $60 \mathrm{~s}$.

Samples resulted positive for the presence of $s t x 2$ gene were tested for $E$. coli 0104 serogroup-associated gene. Sample positive for the presence of $s t x 1$ and/or stx 2 in association with eae gene were tested for the detection of $E$. coli 0103, 0111, 0145, 0157, 026, serogroup-associated genes. Serogroup specific PCR reactions were conducted in a $25 \mu \mathrm{L}$ 
reaction volume using the following reaction mixture: $1 \mathrm{X}$ Taqman ${ }^{\circledR}$ Universal PCR Master mix (Applied Biosystems), 900nM each of the forward and reverse primers, $250 \mathrm{nM}$ of the labeled probe and $4 \mu \mathrm{L}$ DNA template. The PCR instrument and program were the same used for the previous reaction.

When serogroup-associated genes were detected, the isolation of the strain from the enrichment sample broth was attempted. Enriched samples were plated on Tryptone Bile $\mathrm{X}$-Glucuronide (TBX) agar and incubated for $18-24$ h at $37 \pm 1^{\circ} \mathrm{C}$. Up to 50 colonies with $E$. coli morphology were picked up and pointinoculated on Nutrient agar (NA). Pools of 10 colonies were tested by real time PCR for the presence of virulence genes eae, stx 1 and stx2, afterward colonies from positive pools were tested singularly in order to identify STEC strain. In the case of positive molecular detection of virulence genes, and lack of cultural isolation of the strain, the sample is suspected of containing a STEC (presumptive positive).

In the subsequent data analysis, samples constituted by 5 sample units were counted as one sample. If all the sample units resulted negative, the sample was classified as negative, if at least one sample unit resulted positive the sample was classified as positive.

\section{Results}

Eighty (11.6\%) meat samples resulted presumptively positive for STEC; among them 34 (4.9\%) resulted positive for $s t x 1$ and/or $s t x 2$ genes and 46 (6.7\%) for stx 1 and/or stx 2 genes in association with eae gene. Fourty-five (6.5\%) samples resulted positive at least at one serogroup (Table 1).

Serogroup 0103, 0104, 0111, 0145, 0157 and 026 associated genes were detected respectively in 9 (1.3\%), $2(0.3 \%), 1(0.1 \%), 27$ (3.9\%), 20 (2.9\%) and $17(2.5 \%)$ meat samples (Table 2). It is worth noting that STEC virulence genes were detected in 41 out of 213 (19\%) fresh sausages from pork meat. STEC were isolated from $4(0.6 \%)$ meat samples: one strain of $E$. coli $0103 e a e+s t x 1+$ was isolated from fresh meat pork sausage, one strain of $E$. coli $0157 \mathrm{eae}+$ sxt $1+$, stx $2+$ was isolated from bovine minced meat, one $E$. coli 0157 eae+ stx $2+$ and one $E$. coli 0103 eae + stx $1+$ were isolated from bovine hamburgers.

Five (1.8\%) vegetable samples resulted presumptively positive for STEC; among them 4 (1.5\%) samples (2 samples of salad and 2 samples of soya beans) were positive for stx 1 and/or stx 2 genes and $1(0.4 \%)$ sample of salad resulted positive for $s t x 2$ in association with eae gene; no serogroup-associated genes were detected (Table 3 ).

\section{Discussion}

This study reports on a two year STEC monitoring plan carried out in Emilia Romagna Region. Reported results show that 80 of 689 (11.6\%) meat samples and 5 of 273 (1.8\%) vegetable samples were presumptively contaminated by STEC. Cultural method allowed isolation of only 4 STEC strains, out of 689 meat samples tested.

In case of STEC, since the indirect evidence of the virulence genes presumptively determines the presence of the bacteria, the isolation of the strain is needed to confirm the presence of $s t x$ genes in addition to relevant virulence factor in the same live cell whilst excluding the presence of free DNA or free $s t x$ phages in the enrichment culture (EFSA, 2013). This step can delay identification because of difficulties in developing culture media specifically or differentially allowing the growth of STEC (EFSA, 2013), but is needed as molecular methods could overestimate the real STEC

Table 1. Detection of virulence genes in meat and processed meat products according to the type of foodstuff analyzed.

\begin{tabular}{|c|c|c|c|c|c|}
\hline Foodstuff & & $\begin{array}{l}\text { mber of } \\
\text { d samples }\end{array}$ & $\begin{array}{l}\text { Positive for stx } 1 \\
\text { and/or stx } 2\end{array}$ & $\begin{array}{l}\text { Positive for stx } 1 \\
\text { and/or st } 2 \text { with eae }\end{array}$ & $\begin{array}{l}\text { Positive for one or } \\
\text { more serogroups }\end{array}$ \\
\hline Fresh meat pork sausages & & 213 & 15 & 26 & 27 \\
\hline \multirow[t]{2}{*}{ Minced meat and processed meat products } & Poultry & 208 & 1 & 3 & 3 \\
\hline & Other animal species & 268 & 18 & 17 & 15 \\
\hline Total (\%) & 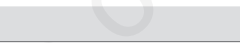 & 689 & $34(4.93)$ & $46(6.68)$ & $45(6.53)$ \\
\hline
\end{tabular}

The number of samples resulted positive at least at one serogroup is also reported.

Table 2. Detection of serogroup-associated genes in meat and processed meat products according to the type of foodstuff analyzed.

\begin{tabular}{llcccccc}
\hline Foodstuff & & 0103 & 0104 & 0111 & 0145 & 0157 & 026 \\
Fresh meat pork sausages & & 6 & 2 & - & 16 & 12 & 5 \\
Minced meat and processed meat products & Poultry & - & - & 1 & 2 & 2 & - \\
\hline & Other animal species & 3 & - & - & 9 & 12 & 6 \\
Total (\%) & & $9(1.31)$ & $2(0.29)$ & $1(0.15)$ & $27(3.92)$ & $20(2.90)$ & $17(2.47)$ \\
\hline
\end{tabular}

Table 3. Detection of virulence genes in fruit and vegetable products according to the type of foodstuff analyzed.

\begin{tabular}{|c|c|c|c|c|}
\hline Foodstuff & $\begin{array}{c}\text { Number of tested } \\
\text { samples }\end{array}$ & $\begin{array}{l}\text { Positive for } \\
\text { stx } 1 \text { and/or stx } 2\end{array}$ & $\begin{array}{c}\text { Positive for } \\
\text { stx } 1 \text { and/or stx } 2 \text { with eae }\end{array}$ & $\begin{array}{c}\text { Positive for } \\
\text { one or more serogroups }\end{array}$ \\
\hline RTE fruits and pre-cut vegetables & 228 & 2 & 1 & - \\
\hline Seeds and sprouted seeds & 45 & 2 & 0 & - \\
\hline Total (\%) & 273 & $4(1.5)$ & $1(0.4)$ & - \\
\hline
\end{tabular}

RTE, ready-to-eat. The number of samples resulted positive at least at one serogroup is also reported. 
contamination.

The level of contamination observed in this study is in line with what has been previously found in other countries (Fantelli and Stephan, 2001; Pradel et al., 2000) and with EU data reported by EFSA (EFSA, 2011). On the contrary, Rantsiou et al. (2012) recently reported $70 \%$ presumptive positivity and $27 \%$ STEC prevalence in meat samples from Piedmont Region. This discrepancy could be due to different types of meat samples included in the analysis.

Even if cattle are considered the major reservoir of STEC, what emerges from our data is that pig could also have a role. Indeed, STEC virulence genes were detected at high frequency (19\%) in fresh sausage made of pork meat and one $E$. coli 0103 strain was also isolated.

Vegetable samples showed low prevalence of presumptive STEC, strain isolation was not attempted since serogroup-associated genes were not detected. Nevertheless, as reported by EFSA, any RTE product contaminated with an isolate of STEC of serogroup 0157, 026, 0103, 0111, 0104 in combination with stx and eae genes should be considered as presenting a potentially high risk for diarrhea and HUS, but for any other serogroups in combination with the same genes, the potential risk is regarded as high for diarrohea and currently unknown for HUS (EFSA, 2013). Our results show that only a sample of salad on 273 might be presumptively included in the latter category.

\section{Conclusions}

Since different types of food are characterized by different risk of being a STEC vehicle to humans (i.e., food to be cooked before con- sumption $v s$ RTE), the evaluation of risk assessment associated with a positive test result should always take into account the type of food involved.

The potential contribution in the epidemiology of human STEC infection related to possible reservoir other than bovine should be further investigated, as highlighted by the high frequency of virulence genes detection and the isolation of one verocytotoxic $E$. coli 0103 strain from pork meat.

\section{References}

Caprioli A, Tozzi AE, Rizzoni G, Larch H, 1997. Non-0157 shiga toxin-producing Escherichia coli infections in Europe. Emerg Infect Dis 3:578-9.

Caprioli A, Morabito $\mathrm{S}$, Brugère $\mathrm{H}$, Oswald $\mathrm{E}$, 2005. Enterohaemorrhagic Escherichia coli: emerging issues on virulence and modes of transmission. Vet Res 36:289311.

EFSA, 2011. STEC/VTEC in humans, food and animals in the EU/EEA technical report, with special reference to the German outbreak strain STEC 0104. Available from: http://www.efsa.europa.eu/it/supporting/pu b/166e.htm

EFSA, 2013. Scientific opinion on VTECseropathotype and scientific criteria regarding pathogenicity assessment. EFSA J 11:1-106.

Fantelli K, Stephan R, 2001. Prevalence and characteristics of shiga toxin-producing Escherichia coli and Listeria monocytogenes strains isolated from minced meat in Switzerland. Int J Food Microbiol 70:639.
ISO, 2012. Microbiology of food and animal feed. Real-time polymerase chain reaction (PCR)-based method for the detection of food-borne pathogens. Horizontal method for the detection of Shiga toxin-producing Escherichia coli (STEC) and the determination of 0157, 0111, 026, 0103 and 0145 serogroups. ISO Norm ISO/TS 13136:2012. International Organization for Standardization Publ., Geneva, Switzerland.

Lindgren SW, Melton AR, O'Brien AD, 1993. Virulence of enterohemorrhagic Escherichia coli 091:H21 clinical isolates in an orally infected mouse model. Infect Immun 61:3832-42.

Nielsen EM, Andersen MT, 2003. Detection and characterization of verocytotoxin producing Escherichia coli by automated 5' nuclease PCR assay. J Clin Microbiol 41:2884-93.

Perelle S, Dilasser F, Grout J, Fach P, 2004. Detection by 5 '-nuclease PCR of Shigatoxin producing Escherichia coli 026, 055, 091, 0103, 0111, 0113, 0145 and 0157:H7, associated with the world's most frequent clinical cases. Mol Cell Probe 18:185-92.

Pradel N, Livrelli V, De Champs C, Palcoux JB, Reynaud A, Scheutz F, Sirot J, Joly B, Forestier C, 2000. Prevalence and characterization of Shiga toxin-producing Escherichia coli isolated from cattle, food, and children during a one-year prospective study in France. J Clin Microbiol 38:102331.

Rantsiou K, Alessandria V, Cocolin L, 2012. Prevalence of shiga toxin-producing Escherichia coli in food products of animal origin as determined by molecular methods. Int J Food Microbiol 154:37-43. 